\title{
Performance Improvement of Axial Compressors and Fans with Plasma Actuation
}

\author{
Sebastien Lemire, ${ }^{1}$ Huu Duc Vo, ${ }^{1}$ and Michael W. Benner ${ }^{2}$ \\ ${ }^{1}$ Department of Mechanical Engineering, École Polytechnique de Montréal, UdM Campus, 2900 Edouard-Montpetit Blvd., \\ 2500 Polytechnique Rd., Montreal, QC, Canada H3T 1J4 \\ ${ }^{2}$ Gas Turbine Laboratory, National Research Council Canada, 1200 Montreal Road, M-10, Ottawa, ON, Canada K1A OR6 \\ Correspondence should be addressed to Huu Duc Vo, huu-duc.vo@polymtl.ca
}

Received 9 June 2009; Revised 31 October 2009; Accepted 2 December 2009

Recommended by Yasuyuki Yokono

\begin{abstract}
This paper proposes the use of plasma actuator to suppress boundary layer separation on a compressor blade suction side to increase axial compressor performance. Plasma actuators are a new type of electrical flow control device that imparts momentum to the air when submitted to a high AC voltage at high frequency. The concept presented in this paper consists in the positioning of a plasma actuator near the separation point on a compressor rotor suction side to increase flow turning. In this computational study, three parameters have been studied to evaluate the effectiveness of plasma actuator: actuator strength, position and actuation method (steady versus unsteady). Results show that plasma actuator operated in steady mode can increase the pressure ratio, efficiency, and power imparted by the rotor to the air and that the pressure ratio, efficiency and rotor power increase almost linearly with actuator strength. On the other hand, the actuator's position has limited effect on the performance increase. Finally, the results from unsteady simulations show a limited performance increase but are not fully conclusive, due possibly to the chosen pulsing frequencies of the actuator and/or to limitations of the CFD code.
\end{abstract}

Copyright (c) 2009 Sebastien Lemire et al. This is an open access article distributed under the Creative Commons Attribution License, which permits unrestricted use, distribution, and reproduction in any medium, provided the original work is properly cited.

\section{Introduction}

The aerodynamic performance of compressors and fans is essentially measured in terms of pressure ratio and efficiency. An increase in either one of these two parameters will inevitably result in an overall benefit to the engine. For example, a pressure ratio increase could allow a reduction in the number of stages for axial compressors and thus a reduction in weight, length and mechanical complexity of the engine. The weight and length reductions are even more important given that a great proportion of the engine weight and length is attributed to the axial compressors [1]. On the other hand, an efficiency increase translates to improvements in fuel consumption.

The pressure ratio is related to the air deflection in each blade row of the stage. The higher the deflection, the higher the pressure ratio and imparted power to the air will be. However, the achievable pressure ratio at a given rotational speed is limited by the growth of the airfoil surface and endwall boundary layers. When the deflection is too high, the suction surface boundary layer separates and the pressure ratio and efficiency decrease rapidly.

This paper presents the results of a preliminary computational investigation of the ability of a new flow control technology, plasma actuation, to control the separation of the airfoil surface boundary layer in highly-loaded compressors. Successful implementation of this technology would ultimately lead to compressor stages with pressure ratio significantly higher than those achievable with conventional designs while maintaining high efficiency.

In the past decades, significant research on boundary layer control technologies in compressors has been carried out. Among them, Loughery et al. [2] found that aspiration of the suction side boundary layer of stator blades was an effective way to reduce losses and deviation angle while increasing the diffusion factor. More recently, Merchant [3] and Schuler [4] showed that aspiration could double the amount of work performed by a compressor stage thus allowing for a significant improvement in pressure ratio while maintaining high efficiencies. Dang et al. [5] 


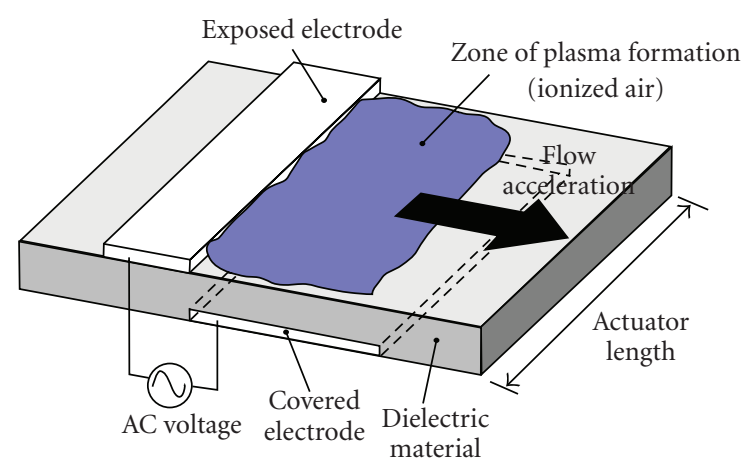

Figure 1: SDBD plasma actuator.

designed an aspirated blade and showed numerically that it could achieve similar performances in comparison to a conventional blade but with a significantly lower solidity. Active control methods have also been used to excite boundary layer structures to enhance the mixing between the low momentum fluid (inside the boundary layer) and the high momentum fluid (outside the boundary layer, core flow). Culley et al. [6] studied the influence of impulsive air injection on a low-speed compressor blade to promote boundary layer reattachment. They found that unsteady injection was a more effective way to reattach the boundary layer than steady injection while requiring a significantly lower fraction of air.

Even though the above mentioned flow control methods showed interesting results from an aerodynamic point of view, the manufacturing and maintenance cost associated with air recirculation and aspiration/injection systems may limit their implementation in real engines.

The advent of the Single Dielectric Barrier Discharge (SDBD) actuator (referred to hereafter as plasma actuators) could provide an interesting alternative. Plasma actuators are a relatively new flow control technology with very promising preliminary results in a variety of low-speed turbomachinery applications such as laminar separation control on turbine blades [7], rotating stall suppression [8], tip clearance flow control in turbines [9] and noise reduction in fans and compressors [10].

A plasma actuator consists of two offset electrodes that are separated by a layer of dielectric material as shown in Figure 1. The application of a high-amplitude (several $\mathrm{kV}$ ) and high-frequency (typically several $\mathrm{kHz}$ ) AC voltage to the electrodes partially ionizes the air over the covered electrode. In the presence of the electric field between the two electrodes, the ionized particles are accelerated and transmit their momentum, through collision, to the neutral air particles in the plasma region over the covered electrode. The result of this process is an acceleration of the air adjacent to the surface of the dielectric. The physics of the ionization and force production processes can be found in references $[11,12]$.

Being electric and without any moving part, plasma actuators offer a response capability over a wide range of frequencies. This capacity allows them to be easily used in steady (continuous) mode as well as in unsteady (pulsed or duty cycle) mode. Moreover, their simplicity and low power consumption also suggest potentially low integration, maintenance and operating costs.

The present work proposes the use of plasma actuators to prevent flow separation on the blade suction side to allow a more aggressive design of compressor blades. A plasma actuator is positioned upstream of the separation zone to add momentum in the boundary layer. Two mechanisms can be used to prevent the separation. The first one is direct momentum addition in the boundary layer through steady (continuous) actuation, while the second aims to enhance the mixing between the high-momentum fluid in the upper part of the boundary layer and the low-momentum fluid adjacent to the surface through resonant excitation of turbulent flow structures inside the boundary layer. This second approach is performed through the operation of the actuator in pulsed mode at appropriate resonant frequencies and could perhaps achieve the same separation suppression as continuous actuation while requiring only a fraction of the power [6].

The objective of this paper is to make a preliminary assessment through CFD simulations of the proposed concept to obtain a reference relatively to the required actuator strength (force generated by the actuator), location and actuation power.

The next section will present the methodology used for this study and the design procedure for the rotor blades. Section 3 will present and discuss the results of the simulations while Section 4 will present the conclusions and suggestions for future work.

\section{Methodology}

A computational approach is the most appropriate way to carry out this preliminary study for two reasons. First, for evaluation of new concepts where the actuator's parameters (actuator strength, position, actuator geometry, etc.) are unknown, it is a lot less expensive and time consuming to carry out CFD simulations than to empirically set up and run experiments. Second, with plasma actuators being still at the research stage, the flow acceleration they can induce is still relatively small to be tested in realistic turbomachinery flow conditions. Consequently, a numerical approach will allow the evaluation of the required actuator strength instead of being limited to the range available with current actuators. However, a numerical approach requires the modeling of the plasma actuator behavior. This section briefly reviews existing SDBD actuator models and describes the model used in this study and its implementation into a CFD code. Subsequently, a brief description of the CFD code and the blade design process will be presented.

2.1. Plasma Actuator Modeling. The modeling of the plasma actuator's effect on the flow is a very active area of research. As such, many models have been and are being developed to simulate their effect on the flow in aerodynamic applications. 
These models can be divided in two main categories: (1) the scientific models aimed at reproducing as exactly as possible the microscopic phenomenon taking place during the ionization process and (2) the "engineering" models or phenomenological models aimed at reproducing the global or macroscopic effects of plasma actuators on the flow.

The models in the first category mainly include those of Roy and Gaitonde [13], Jayaraman et al. [14] and Font et al. [15]. These models simulate the interactions between electrons, ions and neutral particles during the ionization process. Plasma properties are then obtained by solving the continuity, momentum and energy equations for all types of particles involved. The complexity of these models are such that they require considerable computational resources and running time and are thus not yet of practical interest for direct incorporation into simulations of aerodynamic applications. However, they allow to deepen the understanding of the plasma actuator behavior and to show tendencies that can then be implemented in engineering models.

The models in the second category form the majority of the plasma actuator models. They integrate different levels of complexity and as such their computational time varies greatly (from a few seconds to a few hours). The most recent ones model the actuator as a spatial body force distribution. Among the simplest of these models, that of Shyy et al. [16] proposes a time-averaged (over an AC cycle) linear spatial body force distribution based on the size of the electrodes, the actuator's input voltage/frequency and a few properties of air. Suzen et al. [17] developed a more sophisticated model solving the spatial distribution of electric potential and charge density around the actuator as a function of actuator's input voltage magnitude and geometry (electrode length and thickness) and dielectric material properties to obtain a more realistic force distribution. The instantaneous amplitude of the body force vectors is then scaled by the AC voltage input shape to get the variation of the force distribution over time. Orlov et al. $[18,19]$ developed a higher fidelity plasma generation model which more accurately reproduce the time variation of the body force during the AC cycle through the capture of the time variation of the plasma generation. To do this, they divided the region over the dielectric surface into a network of electric circuits to allow the computation of the electric potential distribution along the dielectric surface over the covered electrode at each time step during the AC cycle.

As the level of complexity in the models increases, more and more plasma features are taken into account. However it is important to mention that no model (even the more sophisticated one) can pretend to be able to generate the exact body force distribution corresponding to specific actuator's geometry and input voltage. Moreover, from an analysis of the time scales associated with plasma actuator operation made by Orlov et al. [18], it is reasonable to assume that a time-averaged (over an AC cycle) body force distribution is sufficient to model adequately the plasma actuator behavior in aerodynamic applications. Finally, a comparison of several force distributions by Lemire [20] revealed that although the velocity profile induced by the plasma actuator is not very dependent on the specific body

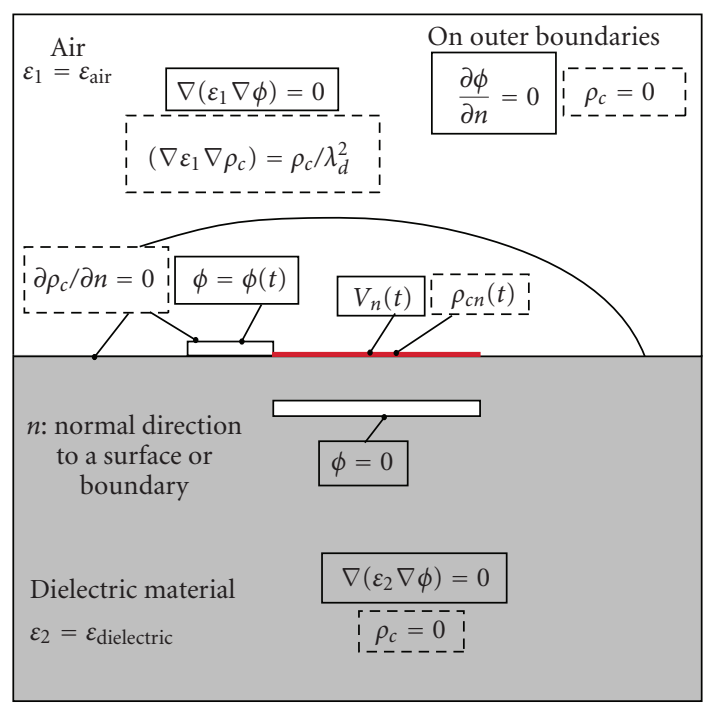

FIGURE 2: Equations and boundary conditions for the hybrid model: equation (1) (solid boxes) and equation (2) (dashed boxes) [20].

force distribution, the power consumed by the actuator is affected by the body force distribution.

Thus, the approach taken in this preliminary study is to simulate the plasma actuator using a time-averaged (over an AC cycle) body force distribution that is as realistic as possible when compared to the body force distribution produced by scientific models.

It was found that a time-averaged body force distribution presenting the same global features as the ones obtained from a scientific model $[21,22]$ could by generated with a "hybrid model" which combines the features of the models of Suzen et al. [17] and Orlov et al. [18]. The hybrid model is described in detail in reference [20]. Figure 2 summarizes the associated equations and boundary conditions used to obtain the spatial force distribution around the actuator. The hybrid model is based on the model presented by Suzen et al. [17] to which certain ideas presented by Orlov et al. $[18,19]$ are added. It basically consists of solving two equations at each time step of the AC cycle, one for the spatial distribution of the electric potential and one for the spatial distribution of the charge density as given by (1) and (2).

$$
\begin{gathered}
\nabla \cdot\left(\varepsilon_{r} \nabla \phi\right)=0, \\
\nabla \cdot\left(\varepsilon_{r} \nabla \rho_{c}\right)=\frac{\rho_{c}}{\lambda_{d}^{2}},
\end{gathered}
$$

where $\varepsilon_{r}$ is the relative permittivity, $\phi$ the electric potential, $\rho_{c}$ the charge density and $\lambda_{d}$ the Debye length (a plasma characteristics).

However, the electric potential distribution $\left(V_{n}(t)\right)$ and the charge density distribution $\left(\rho_{c n}(t)\right)$ are added and computed from the methodology defined in Orlov et al. $[18,19]$ and Lemire [20], respectively, which is briefly summarized below. 


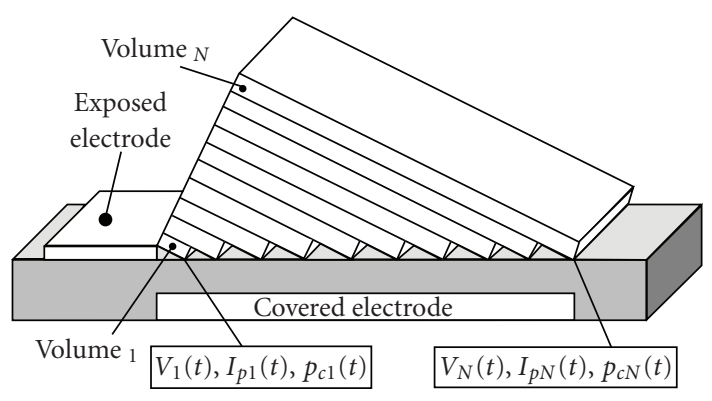

FIgURE 3: Subdivision of the air domain over the covered electrode into $N$ volumes $[19,20]$.

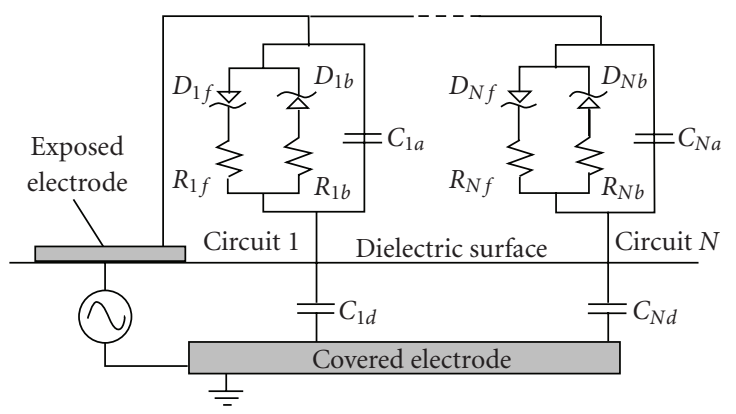

Figure 4: Electric circuits used to compute the properties on the dielectric surface (only circuits 1 and $N$ are shown) [19,20].

The addition of the potential distribution on the dielectric surface over the covered electrode serves two purposes. The first is to reproduce the phenomenon that is seen in plasma actuators which is that charges arrange themselves in such a way as to cancel as much as possible the electric field [11]. The second is to define the plasma extent over the dielectric surface which is known to be dependent of the air electric breakdown voltage. The computation of $V_{n}(t)$ is described in details in $[18,19]$ and will be summarized here. It consists in the subdivision of the domain over the covered electrode into $N$ volumes (Figure 3 ) to which a network of $N$ parallel electric circuits is associated (Figure 4). It can be seen in Figure 3 that there is a direct relationship between the geometric properties of the volume (length, area) and its relative distance from the exposed electrode. These geometric characteristics are used to compute the values of the resistance and capacitance associated with each circuit (Figure 4).

Once the resistances and capacitances corresponding to those of the air and dielectric for each circuit $(n=$ $1,2, \ldots, N)$ are computed, the associated electric potential $V_{n}(t)$ and the current $I_{p n}(t)$ at every time step of the AC cycle can then be obtained from the input voltage properties (amplitude and frequency). The computation of the charge density on the dielectric surface over the covered electrode also differs from the approach taken by Suzen et al. [17]. Instead of the empirical charge density used by Suzen et al. [17], it is computed as a function of the current through the plasma resistance $\left(I_{p n}(t)\right)$ defined in $[18,19]$ and the volume associated to the electric circuit, as in (3). The method is presented in [20]:

$$
\rho_{c n}(t)=\frac{I_{p n}(t) \cdot \Delta t}{\text { Volume }_{n}}, \quad n=1,2, \ldots, N .
$$

Once the boundary conditions are specified, the spatial distributions of electric potential and charge density are solved, at each time step, in the computational domain from (1) and (2). The body force distribution, per unit actuator length (actuator length as defined in Figure 1) can then be computed with (4):

$$
\vec{F}=\rho_{c} \vec{E} A=\rho_{c}(-\nabla \phi) A[N / m] .
$$

The actuator geometry used with the hybrid model to obtain the spatial force distribution used throughout the project has $0.0254 \mathrm{~mm}$ thick electrodes and their respective lengths are $5 \mathrm{~mm}$ (exposed) and $12.7 \mathrm{~mm}$ (covered). Figure 5 shows the associated time-averaged spatial body force distribution. The main characteristics of this force distribution are in good agreement with those generated by complex scientific models $[21,22]$, namely a force directed in the positive $x$-direction at the junction of the two electrodes, a small force at the end of the covered electrode that is directed in the negative $x$-direction and finally a resultant force in the $y$-direction that is directed toward the surface over the covered electrode.

2.2. CFD Implementation. The plasma actuator model is implemented in the CFD code as the spatial body force distribution obtained in Section 2.1 and shown in Figure 5. As previously mentioned, a time-averaged body force distribution is sufficient to adequately model the plasma actuator behavior. The desired integrated (total) force produced by the plasma actuator, henceforth referred to as actuator strength, is obtained by multiplying the magnitude of the force vectors in Figure 5 by a scaling factor. This methodology assumes that the spatial body force distribution is unchanged as the actuation strength changes. A similar approach has also been used by Gaitonde et al. [21] and Vo [23]. Moreover, since the exposed electrode is very thin and could in practice be mounted flush with the blade surface, its protrusion above the surface is neglected and is not modeled in the CFD simulations.

The simulations carried out in this study have been performed using UNSTREST [24], an established 3-D cellcentered time-accurate RANS turbomachinery CFD code developed by J. Denton of the University of Cambridge Whittle Laboratory. The code uses a mixing-length turbulence model and a wall function. The methodology used to transfer the actuator effects from the actuator model to the CFD mesh is explained in $[10,20]$. Figure 6 shows the transferred force distribution of Figure 5 onto the curved surface of a compressor blade.

2.3. Blade Design. To generate the different blades used throughout this project, a through-flow program has been developed to offer the flexibility to design the blade according 
to a prescribed spanwise loading coefficient with control on the cross section profiles used along the span. This program was used to create 3-D blades and the associated gas paths and to predict the approximate performance from a series of common parameters such as: inlet temperature and pressure, stage dimension ( $r_{\text {tip }}$, hub-to-tip ratio), solidity, aspect ratio, Mach $_{\text {tip }}$ and flow coefficient at the design point. The loading coefficient (5) was used as the design variable for the different blades:

$$
\psi=\frac{\text { absoulute tangential velocity variation }}{\text { rotational speed }} \text {. }
$$

As such, a spanwise distribution of load coefficient was used to create the different blade cross sections. Losses and deviation correlation used in the program were obtained from results presented in $[1,25]$, respectively.

\section{Numerical Simulations}

To assess the effectiveness of plasma actuator to increase the performance of axial compressors, two types of simulations have been carried out. The first type aims to establish the performance of rotor blades that do not integrate flow control method on their surface. These rotors will be defined as "conventional rotors" and will be used as a reference to evaluate the effectiveness of plasma actuators. The second type of simulations concerns rotor blades with plasma actuators on their suction surface to prevent flow separation. All the simulations carried out in the project have been performed on a single rotor blade passage configuration using a $127 \times 45 \times 45($ axial $\times$ pitch $\times$ radial $)$ structured mesh. For all geometries, the computational domain extends at least 1.5 pitch upstream and downstream of the blade. Figure 7 shows the computational domain and the approximate position of the actuators that will be used in Section 3.2.

All rotor blades have been designed using the methodology presented in Section 2.3 and the simulations have all been performed in time-accurate mode. The inlet boundary conditions, identical for all simulations, consist of uniform stagnation pressure and temperature and axial inlet flow. The outlet conditions consist in the imposition of a circumferentially uniform casing static pressure with radial equilibrium. This pressure is adjusted to obtain the same mass flow (design mass flow) (within 0.04\%) for all simulated rotor geometries. The boundary layers are assumed turbulent along the blade passage given the positive pressure gradient in the blade passage.

Due to the relative limitation in the performance of plasma actuator (in the near future) and to avoid unnecessary complexity brought about by shock, subsonic rotors have been chosen in this preliminary study. The hub-to-tip ratio, flow coefficient, aspect ratio and solidity of the blades have been chosen to correspond approximately to those found in the first stages of low pressure compressors. Finally, to isolate the effect of flow turning on rotor performance, it has been decided to use the same cross section profile (modified NACA 65006) all along the blade span and the same stacking point ( $45 \%$ of the camber line). This methodology also limits the number of design parameters

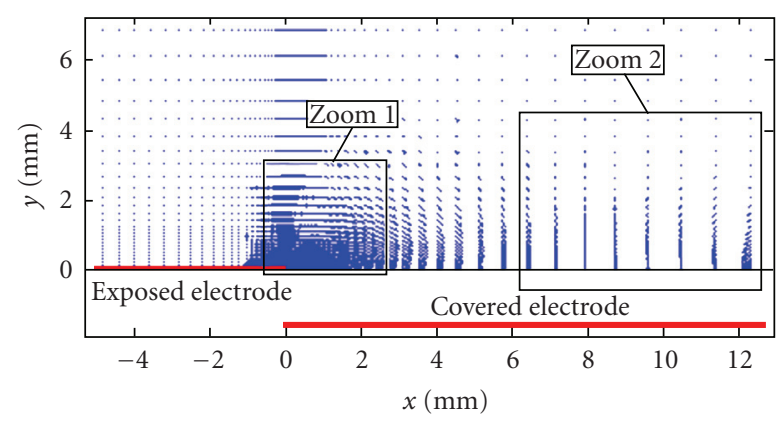

(a) Spatial distribution of the force.

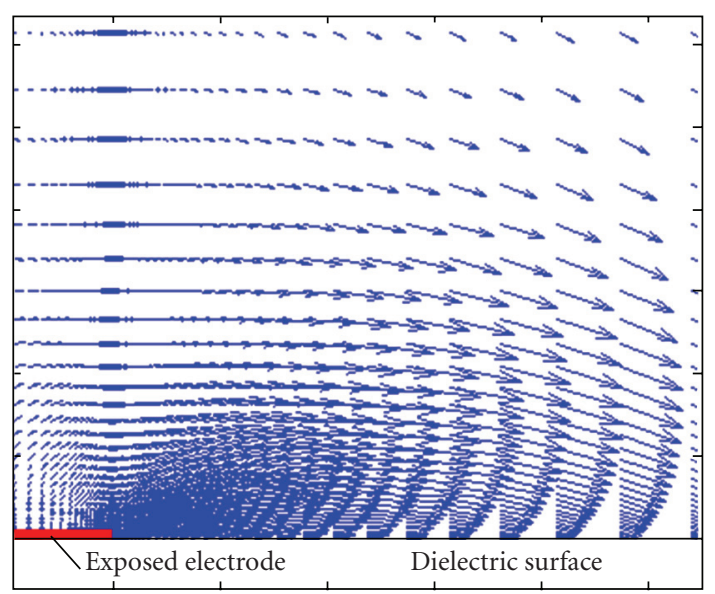

(b) Zoomed region 1 .

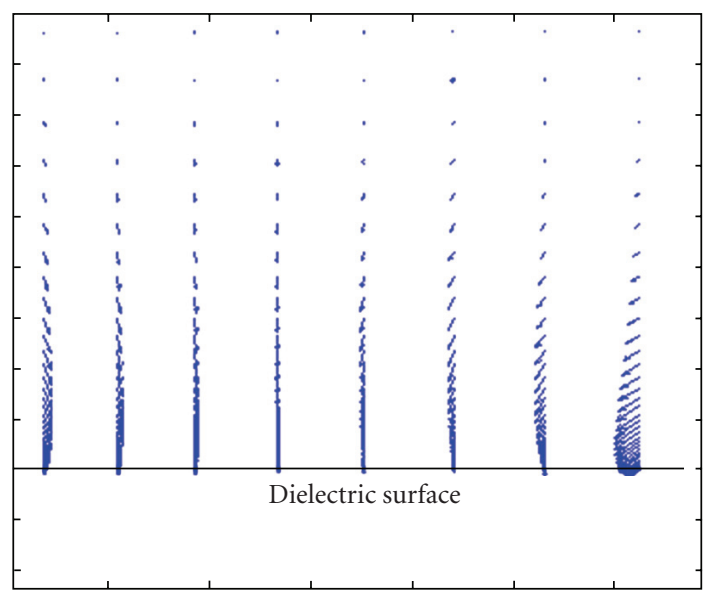

(c) Zoomed region 2 .

FIGURE 5: Time-averaged spatial force distribution generated by a plasma actuator from the "hybrid" model.

to only the spanwise loading coefficient distribution which is of interest as the objective of this project is to evaluate the benefits of plasma actuators on flow turning capability and resulting performance enhancement. The parameters that have been used to design the blades are presented in Table 1.

The following two Sections (3.1 and 3.2) will present the results from the two types of simulations and Section 3.3 and 3.4 will discuss the results. 


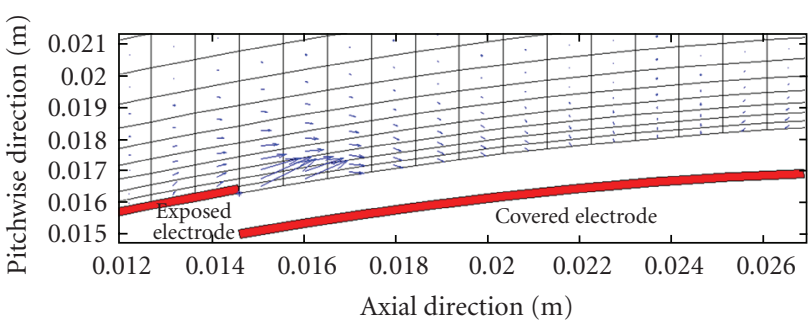

FIGURE 6: Mapping of the actuator's force distribution onto a blade suction surface mesh.

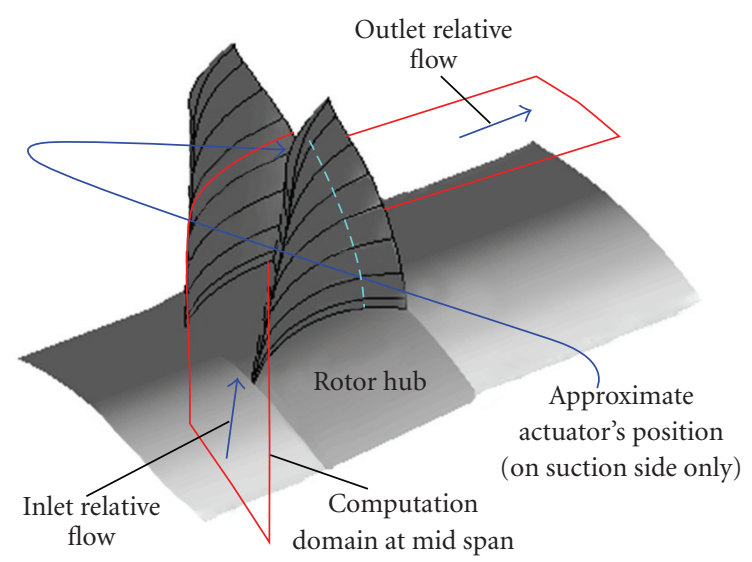

Figure 7: Computational domain used in the simulations (only one blade passage is used in the simulation) and approximate position of the actuator (the actuator is on the suction side only).

TABLE 1: Design parameters of the blades.

\begin{tabular}{lc}
\hline Tip Mach number & 0.5 \\
Tip Radius & $0.3 \mathrm{~m}$ \\
Inlet hub-to-tip ratio & 0.70 \\
Inlet absolute flow angle & $0^{\circ}$ \\
Mid Span Solidity & 1.16 \\
Aspect Ratio & 1.15 \\
Mean Flow coefficient & 0.6 \\
Inlet Total Pressure & $101300 \mathrm{~Pa}$ \\
Intel Total Temperature & $300 \mathrm{~K}$ \\
\hline
\end{tabular}

3.1. Conventional Blade Simulations. Ten rotor blade geometries have been simulated to establish the performance range that can be achieved with conventional blades. The lowest pressure ratio blade (Figure 8) does not exhibit suction side boundary layer separation along its span. The objective of this first blade is to set a starting point from which the loading coefficient could be increased at the different cross sections in order to design the other blades.

Three output parameters have been studied to evaluate the performance of the blades: the pressure ratio (total-tototal), the power transmitted to the air by the rotor and the

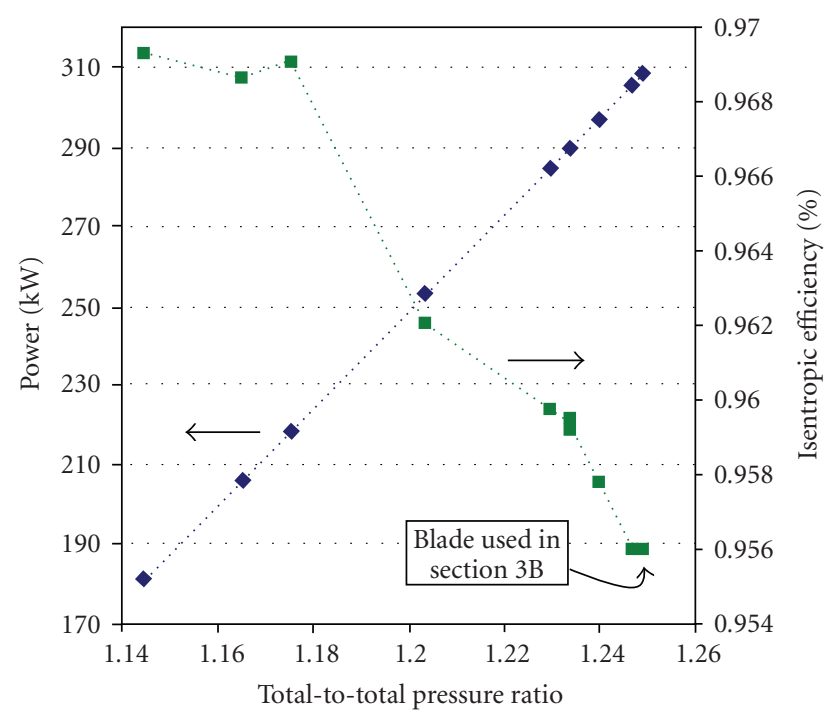

FIGURE 8: Pressure ratio and isentropic efficiency of conventional blades.

isentropic efficiency (as defined by (6)). The results of these simulations are presented in Figure 8:

$$
\eta=\frac{h_{02, \text { isentropic }}-h_{01}}{h_{02}-h_{01}} .
$$

The results show that the power increase significantly with pressure ratio, while the opposite is observed for the efficiency. This situation is explained by the fact that for the blades having a pressure ratio at or above 1.204, the flow on the suction side of the blade begins to separate, thus increasing the losses and consequently decreasing the efficiency. The separation then becomes more important as the pressure ratio increase due to the higher loading coefficients.

The results presented in Figure 8 also show that the efficiency decreases by more than $1 \%$ between the most and least efficient blades.

The analysis of the flow field for the blade with the lowest efficiency reveals that it presents separation zones all along its span. This blade then constitutes a good candidate for the evaluation of plasma actuators to increase the performance of compressor blades. This study will be presented in the next section.

Figure 9 presents the loading coefficient distribution along the span and the associated cross section of the blade at a few span positions for the blade that will be used for actuation in Section 3.2. The loading coefficient distribution of the blade without suction side boundary layer separation at a pressure ratio of 1.175 is also presented for comparison.

3.2. Actuated Blade Simulations. Section 3.1 has allowed to define a blade having separation zones all along its span. The purpose of this section is to evaluate how plasma actuators could suppress these separation zones in order to increase the pressure ratio, efficiency and power of the rotor blades. 


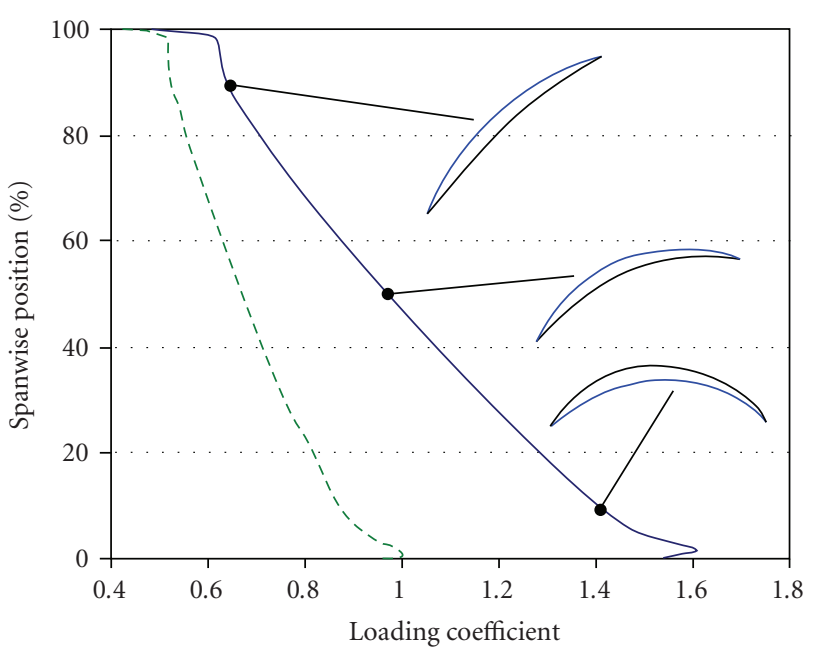

FIGURE 9: Loading coefficient distribution and cross sections for the blade used in Section 3.2 (solid line) and the blade having a pressure a ratio of 1.175 (dashed line).

As mentioned in Section 1, the purpose of plasma actuator is to add momentum in the boundary layer either directly with steady actuation or indirectly through pulsed actuation at a resonant frequency of the turbulent boundary layer structures to enhance the mixing between the outer high momentum fluid and the low momentum fluid near the surface. As such, two categories of simulations have been carried out to evaluate the boundary layer reattachment capability of plasma actuators. This section presents the actuation parameters used in the simulations while Section 3.3 will present the results.

Figure 10 shows the axial velocity contour lines at $60 \%$ of the blade span. The region between $40 \%$ and $80 \%$ of the blade span presents the biggest separated region. In Figure 10, the three actuator positions to assess are identified: (1) just upstream of the separation zone, (2) at the beginning of the separation zone (inside the separation zone) and (3) at the point where the flow begins to slow down on the suction side. The actuator position is defined by the location of the beginning of the covered electrode that is facing the exposed electrode ( $x=0$ in Figure 5). These three actuation positions have been established for each section along the span.

Category 1: Steady Actuation. Nine simulations have been carried out with continuous actuation to evaluate the effect of actuator strength and position on the performance increase. For each actuator location, three actuator strengths have been simulated: $1 \mathrm{~N} / \mathrm{m}, 2 \mathrm{~N} / \mathrm{m}$ and $4 \mathrm{~N} / \mathrm{m}$. Although, the actuator strength used in this project are significantly higher than those of the first generation of plasma actuators $[26,27]$, new technologies currently under development [28, 29] could significantly increase the level of actuator strength. Moreover, as mentioned previously, the goal of this paper is not to simulate what can be achieved with the current level of actuator strength but more to establish what actuator strength is required to suppress the separated flow.

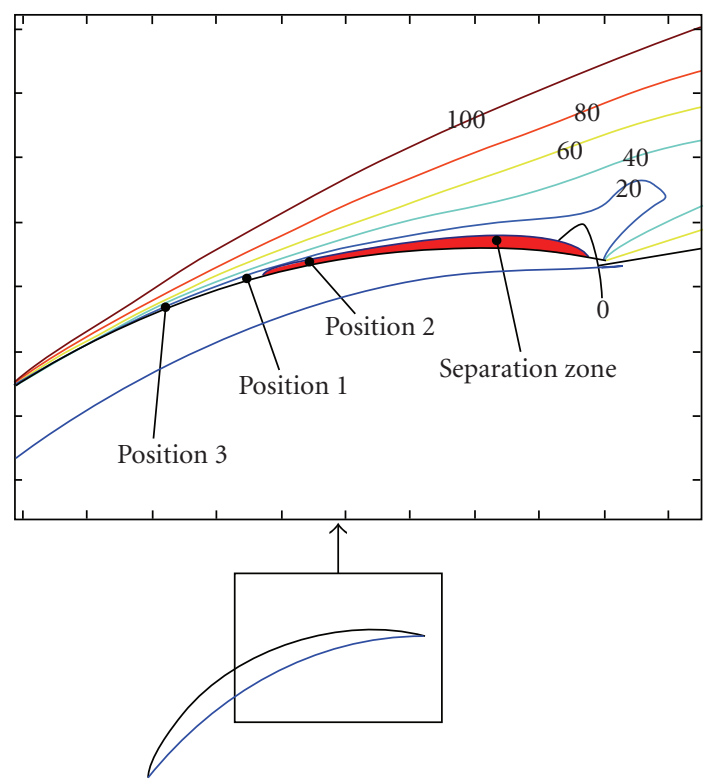

FIgURE 10: Axial velocity contour lines $(\mathrm{m} / \mathrm{s})$ and the positions at which plasma actuators are positioned.

Category 2: Unsteady Actuation. Six simulations have been performed with pulsed actuation. Their objective is to evaluate the effect of the pulsing frequency on the mixing enhancement, wake reduction and separated zone suppression. All the simulations used an actuator strength of $2 \mathrm{~N} / \mathrm{m}$. Only two actuator positions have been simulated: position 2 and 3. The pulsing frequency has been established from a method that has been validated experimentally by Huang [7] and Culley et al. [6] and is based on the Strouhal number defined by (7):

$$
S t=\frac{f \cdot d}{V},
$$

where $f$ is the forcing frequency, $d$ is the distance from the actuator position to the trailing edge (for position 2 this distance correspond to the length of the separated region) and $V$ is the local freestream velocity.

From $[6,7]$, it can be found that the most effective forcing frequency corresponds to a Strouhal number of 1 . It is assumed that this Strouhal number is applicable to our cases because Culley et al. [6] was also studying flow in a compressor. Moreover, it has been shown that this Strouhal number is also applicable in turbine flows [7].

To define the forcing frequency, the flow properties at $60 \%$ of the span have been used due to its large separation zone along the blade span. From these flow properties the frequency corresponding to a Strouhal number of 1 has been established to be on the order of $2000 \mathrm{~Hz}$. To take into account the potential uncertainty on this value, simulations have also been carried out with frequencies of $1000 \mathrm{~Hz}$ and $400 \mathrm{~Hz}$. The duty cycle (fraction of the time during which the actuation is on over a period) has been held constant at $25 \%$ throughout the simulations, based on results presented by Huang [7] where it was found that a duty cycle of $10 \%$ was 


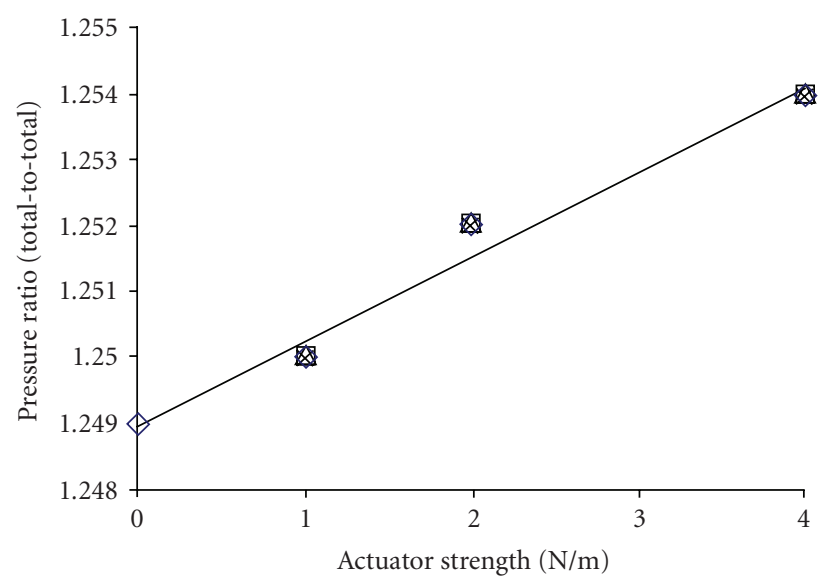

(a)

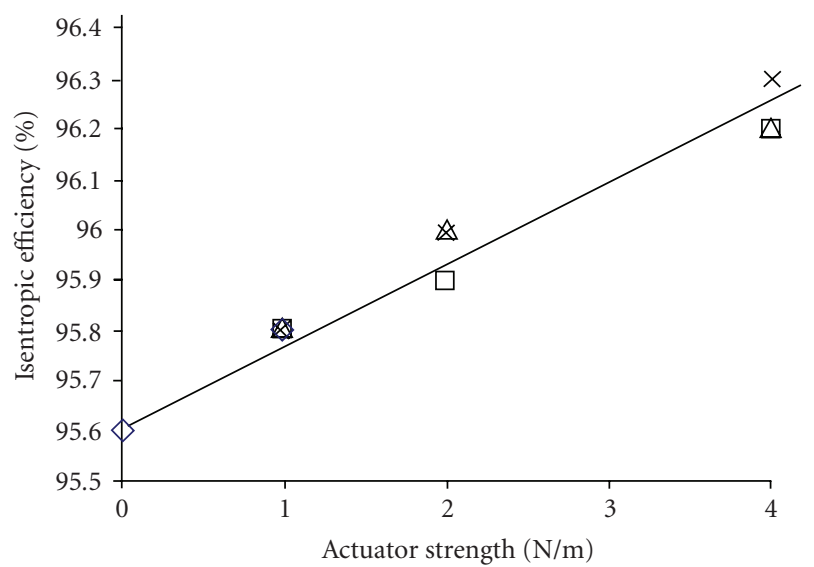

(b)

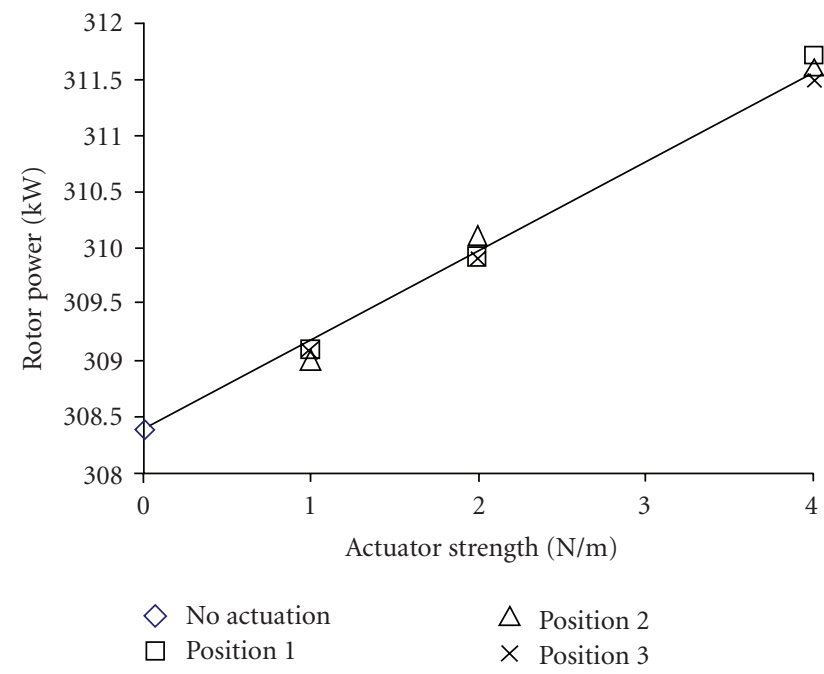

(c)

FIGURE 11: Effect of actuator strength and position on compressor performance for steady actuation.

as effective as a duty cycle of $50 \%$ to suppress boundary layer separation on a turbine blade.

3.3. Results. To evaluate the influence of plasma actuation on the rotor performance, three parameters have been considered for comparison with the reference case: the totalto-total pressure ratio, the isentropic efficiency and the power that must be provided to the actuator relative to the increase in power imparted to the air by the rotor. The results are presented in Table 2 and obtained from mass-averaged properties. For unsteady actuation, the results are also timeaveraged over one period of actuation. The power provided to the actuator is estimated from (8):

$$
P=\sum_{n=1}^{N_{-} \text {cells_domain }}|\vec{F} \cdot \vec{v}|
$$

where $\vec{F}$ is the actuator force vector and $\vec{v}$ is the velocity vector.

Figure 11 plots the results for steady actuation shown in Table 2.
Table 2 indicates that steady actuation is the most effective way to increase rotor performance. On the other hand, unsteady actuation only has limited impact on performance, at least on a time-averaged basis. The following subsections will first discuss the results.

3.3.1. Effect of Actuation Strength (Steady Actuation Cases). Actuation strength has a significant impact on all three parameters used to measure the blade performance. Figure 11 shows that pressure ratio, efficiency and rotor power vary almost linearly with actuator strength. The flow field analysis for cases 2 to 4 shows the net influence of the actuator strength on the reduction of the separation zone. These results are presented in Figure 12 for a spanwise position corresponding to $60 \%$. It can be seen that for an actuator strength of $1 \mathrm{~N} / \mathrm{m}$ and $2 \mathrm{~N} / \mathrm{m}$, the separation zone is still important, even though it is smaller than the one for the reference case (case 1). For an actuator strength of $4 \mathrm{~N} / \mathrm{m}$, the separation zone is almost totally eliminated. Similar results have also been obtained for the other actuator positions 


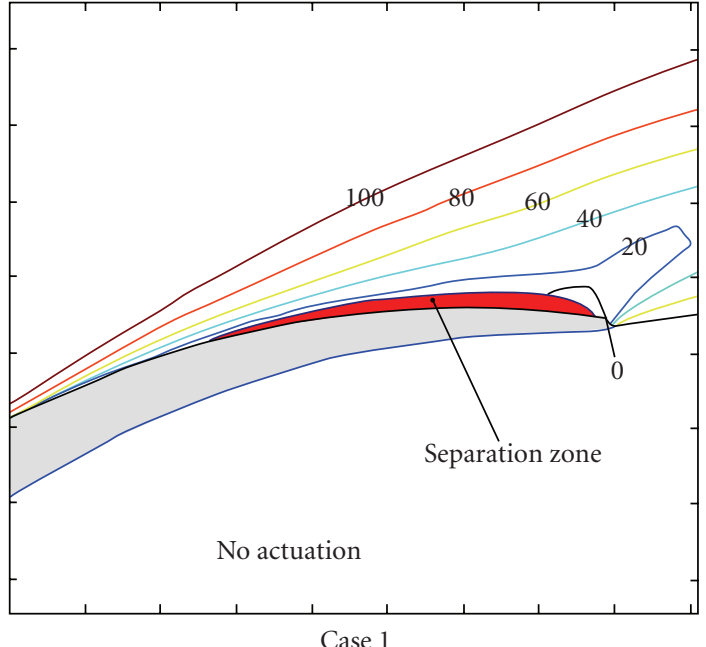

(a)

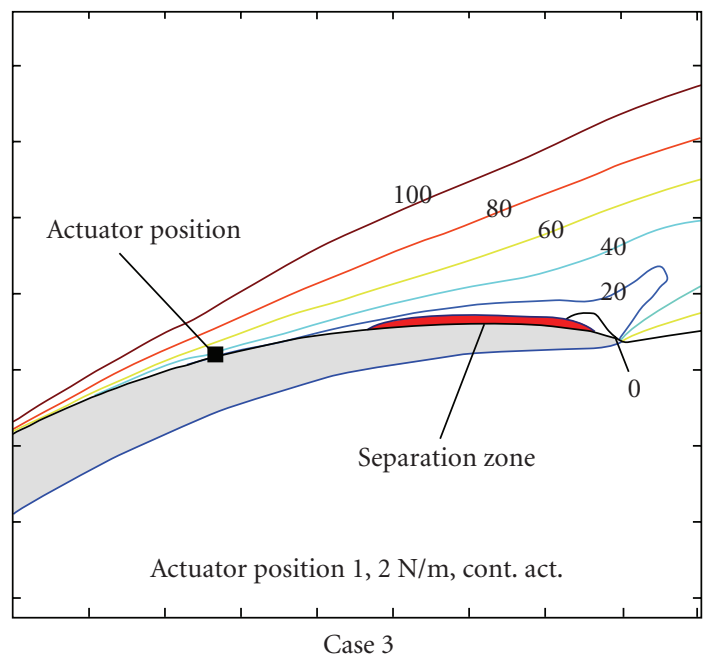

(c)

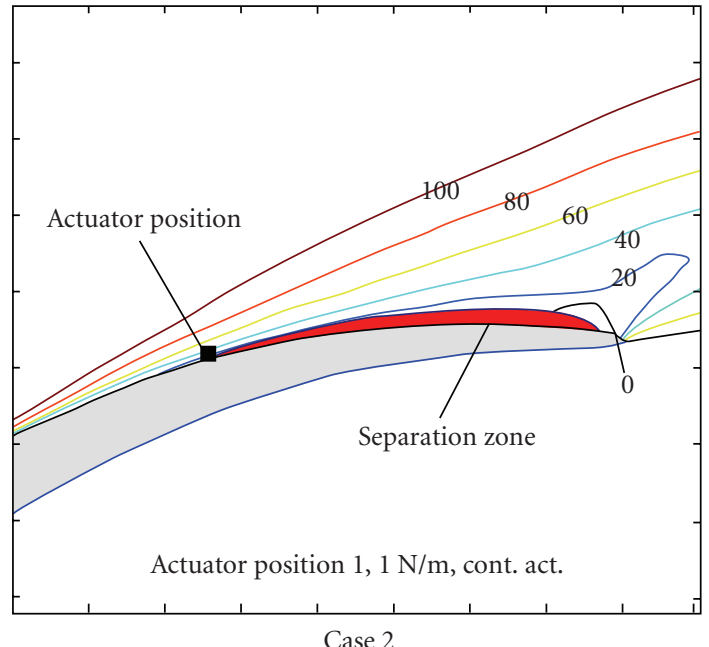

(b)

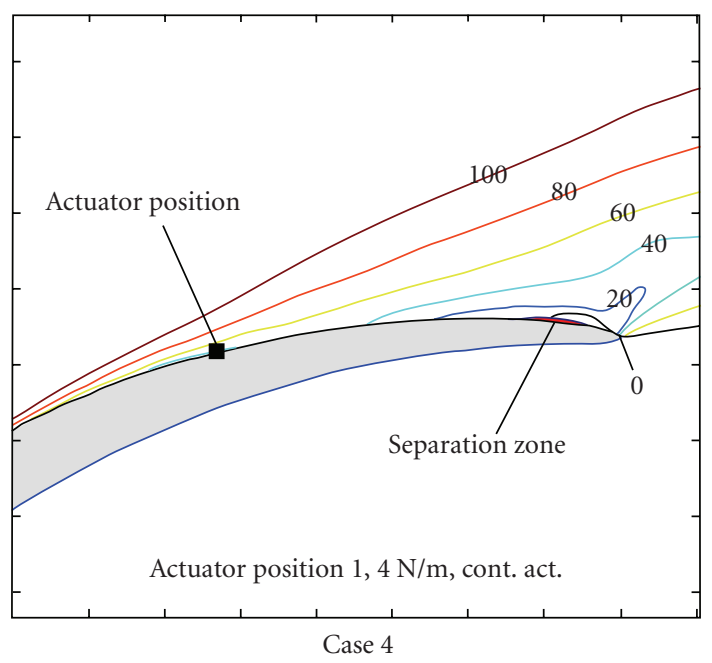

(d)

FIGURE 12: Effect of actuator strength on the separated region for cases 1 to 4 .

(cases 5 to 10) except for case 7 where the separation has been totally eliminated. Figure 13 presents how the separation zones along the span have been influenced by the actuator located at position 1. The same conclusion drawn for the 60\% span location still apply: (1) as the force is increased, the separation zones diminish and (2) for an actuator strength of $4 \mathrm{~N} / \mathrm{m}$ the separation is totally eliminated along the blade except for the $60 \%$ span region.

The analysis of the power that must be given to the actuator relatively to the power increase of the rotor (see Table 2) also show that plasma actuator are a very effective way to increase the power of the rotor. For example, for case 4 , the power that must be given to the actuator corresponds to $0.22 \%$ of the rotor power while it allows a $1.1 \%$ increase in rotor power.

3.3.2. Effect of Actuator Position (Steady Actuation Cases). The effect of the actuator position on the pressure ratio, efficiency and power increase is almost imperceptible. However, its effect is very important on the power that must be submitted to the actuator. The main reason for this power gap between positions 1, 2 and 3 is the fact that at position 1 and 2 the fluid velocity is relatively small because of the recirculation zone, while at position 3 the flow begins to decelerate but its velocity is still important. Therefore, at position 3, the actuator must impart momentum to a larger amount of fluid particles over a given time than at position 1 and 2.

Even though in the present simulations, actuators positioned at locations 1 and 2 seem to be more effective than at location 3 (from an energy point of view), practical consideration may limit this advantage. Compressor blades being relatively thin near their trailing edge, structural constraints may inhibit the integration of plasma actuators in this region. For that reason, position 3 could offer a better location. Therefore, the optimal position could be a compromise between energy and structural/geometrical 
TABLE 2: Simulated cases and results.

\begin{tabular}{|c|c|c|c|c|c|c|c|}
\hline \multicolumn{4}{|c|}{ Simulations } & \multicolumn{4}{|c|}{ Results } \\
\hline Case & & Actuator & Pulsing & Total-to-Total & Isentropic & Rotor & Actuator \\
\hline \multirow{2}{*}{ Number } & Position & Strength & Frequency & Pressure & Efficiency & Power & Power \\
\hline & (Figure 10) & $(\mathrm{N} / \mathrm{m})$ & $(\mathrm{Hz})$ & Ratio & $(\%)$ & $(\mathrm{kW})$ & $(\mathrm{kW})$ \\
\hline 1 & \multicolumn{3}{|c|}{ Reference case (no actuation) } & 1.249 & 95.6 & 308.4 & - \\
\hline \multicolumn{8}{|c|}{ Steady Actuation (continuous actuation) } \\
\hline 2 & 1 & 1 & - & 1.250 & 95.8 & 309.1 & 0.12 \\
\hline 3 & 1 & 2 & - & 1.252 & 95.9 & 309.9 & 0.29 \\
\hline 4 & 1 & 4 & - & 1.254 & 96.2 & 311.7 & 0.70 \\
\hline 5 & 2 & 1 & - & 1.250 & 95.8 & 309.0 & 0.11 \\
\hline 6 & 2 & 2 & - & 1.252 & 96.0 & 310.1 & 0.26 \\
\hline 7 & 2 & 4 & - & 1.254 & 96.2 & 311.6 & 0.64 \\
\hline 8 & 3 & 1 & - & 1.250 & 95.8 & 309.1 & 0.21 \\
\hline 9 & 3 & 2 & - & 1.252 & 96.0 & 309.9 & 0.45 \\
\hline 10 & 3 & 4 & - & 1.254 & 96.3 & 311.5 & 0.99 \\
\hline \multicolumn{8}{|c|}{ Unsteady Actuation (pulsed actuation) ${ }^{*}$} \\
\hline 11 & 2 & 2 & 400 & 1.250 & 95.7 & 308.3 & 0.18 \\
\hline 12 & 2 & 2 & 1000 & 1.250 & 95.7 & 308.6 & 0.18 \\
\hline 13 & 2 & 2 & 2000 & 1.250 & 95.7 & 309.0 & 0.20 \\
\hline 14 & 3 & 2 & 400 & 1.250 & 95.7 & 309.2 & 0.40 \\
\hline 15 & 3 & 2 & 1000 & 1.250 & 95.8 & 309.3 & 0.40 \\
\hline 16 & 3 & 2 & 2000 & 1.250 & 95.7 & 308.6 & 0.40 \\
\hline
\end{tabular}

*For unsteady actuation, the duty cycle used in the simulations is $25 \%$.

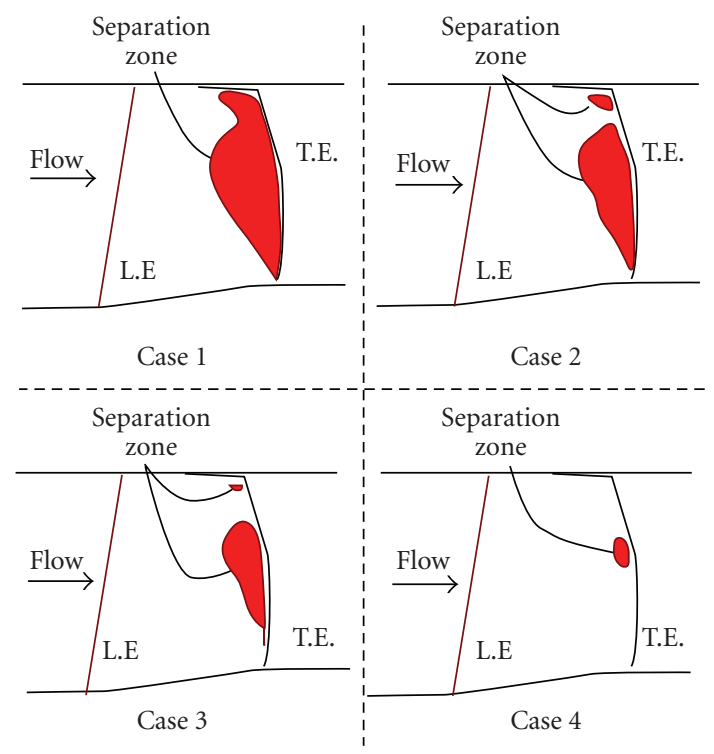

FIGURE 13: Evolution of the separated flow region (on the suction side) all along the span for an actuator located at position 1.

considerations. In addition, the insensitivity of the increase in pressure ratio and efficiency with respect to actuator position allows for a more radial actuator along the span rather than one that needs to follow the shape of the suction side boundary layer separation line.
3.3.3. Unsteady Actuation. Even though the results from unsteady actuation show a certain increase in the performance of the blade on a time-averaged basis, an analysis of the flow field at different times during the duty cycle period reveals that the objective pursued by pulsed actuation is not reached. While unsteady actuation aims to bring in momentum from the outer fluid to the fluid adjacent to the surface through enhanced mixing, the simulations indicate that the only momentum imparted to the fluid comes from the actuator itself. This conclusion is confirmed by the analysis of the variation of the flow properties over several cycles of actuation as shown in Figure 14 for case $12(2 \mathrm{~N} / \mathrm{m}$, $1000 \mathrm{~Hz}$ ). It can be observed that when the actuator is on, the imparted momentum tend to increase the performance of the rotor. This performance increase is due to the fact that when the actuator is on, the momentum imparted by the actuator contributes to push the very low momentum fluid downstream of the blade. As a result, the aerodynamic blockage caused by the thick boundary layer diminishes and the pressure ratio, efficiency and power increase. On the other hand, when it is off, the performance tends to get back to the one obtained when there is no actuation (case 1). Moreover, the comparison of the results for case 12 with those for case 6 (same actuation parameters, but in continuous mode) shows that the average performances obtained in case 12 are far from the one obtained in case 6 . Thus, this observation shows that unsteady actuation is a lot less effective than continuous actuation.

Consequently, the results only show a significant impact when the actuator is on and almost nothing when it is off. 


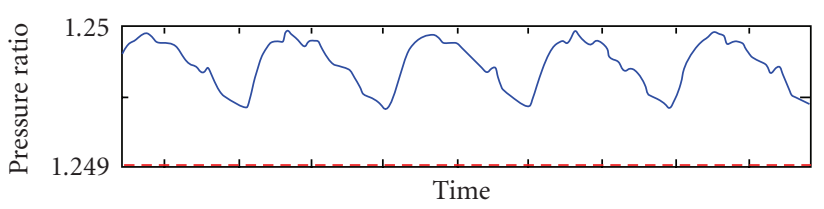

(a)

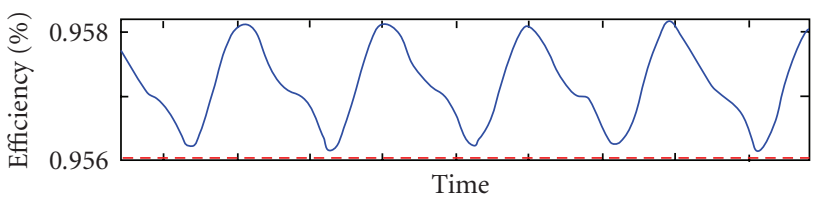

(b)

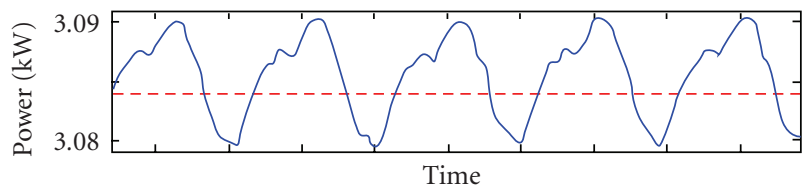

(c)

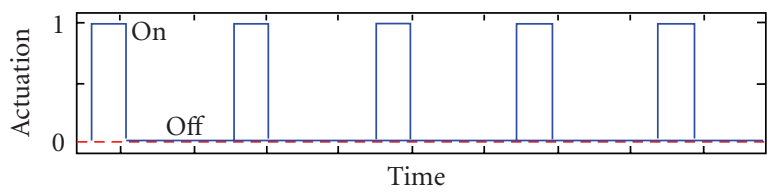

(d)

FIGURE 14: Variation of the flow properties over time for case 12 (solid line) and comparison with the reference case (case 1) (dashed line).

Two factors could explain the observed situation. The first one is that the frequencies simulated are not close enough to the resonant frequencies. The second factor is related to the mesh and CFD code used. Through their turbulence model, RANS CFD codes average the effect of the small turbulent structures whose size are smaller than that of the mesh. Therefore, if those are the structures that are excited by pulsed actuation, then the effect cannot be captured. Similar conclusions have been obtained previously by Lemire and Vo [10] for pulsed actuation. However, in the present work, a validated method to define the pulsing frequency was available $[6,7]$, which is what justified the evaluation of pulsed actuations in the present cases.

3.4. Implications. The analysis of the results carried out in Section 3.3 demonstrated that plasma actuators allow performance improvement of a given rotor blade geometry compared to its performance without actuation while consuming very little power relative to the power imparted to the air by the rotor. This section will briefly outline how plasma actuators allow to improve the performance with respect that obtained with conventional blades (see Section 3.1). To perform this comparison, the performance obtained in case 10 (see Table 2) will be used (case 10 has offered the best performance increase).

According to Figure 8, a conventional blade with the efficiency of case $10(96.3 \%)$ can achieve a pressure ratio and imparted power on the order of 1.195 and $215 \mathrm{~kW}$, respectively. This means that an equivalent plasma actuated blade (case 10) can achieve an increase in pressure ratio of about $5 \%$ and in rotor power of about $16 \%$, while consuming $0.4 \%$ of the rotor power to operate the actuators. Higher actuator strength and/or multiple actuators placed along the chord would allow for larger increase in performance. In addition, the proposed concept can obviously also be applied to stator blades for improved stage performance.

Thus, significant improvement can be achieved by the integration of plasma actuator into the design of high pressure ratio compressor blades.

\section{Conclusion}

This paper presents a preliminary study, through CFD simulations, of the potential of plasma actuators to suppress the flow separation over a compressor blade in order to increase its pressure ratio, efficiency and power. Simulations have been carried out to evaluate the effect of three parameters: actuator strength, actuator position on the blade and actuation method (steady versus unsteady).

Of the three parameters taken into account, actuator strength is the one that has the most significant impact on the performance increase of the blade. Moreover, an almost linear correlation has been found between the actuator strength and the pressure ratio, efficiency and rotor power. The effect of the position is relatively negligible on the performance increase but has a significant impact on the power supplied to the actuator. The further upstream the actuator is from the beginning of the separation zone the more power will have to be supplied to it. Finally, the assessment on the actuation method is not conclusive possibly due to the frequencies used to excite the turbulent structure of the boundary layer or to the size of the excited flow structures being too small to be resolved with the mesh used in the present RANS CFD code.

From an energy stand point, plasma actuators have shown to be very efficient. They allow significant power increase of the rotor while requiring a relatively small amount of power.

Even though simulations were carried out on compressor blades, the concept studied in this project is also applicable to fan blades.

Due to the limitation encountered with pulsed actuation, future work should focus on the evaluation of other forcing frequencies and on the establishment of the capability of CFD codes to capture the resonant effect of the forcing frequency. To define the forcing frequencies, numerical probes monitoring the fluctuation of the relative velocity on the blade surface could be used. From these signals the dominant (resonant) frequencies can be identified at which pulsed actuation can be applied. Low-speed simulations using simple 2D geometry might allow to validate existing experimental results of pulsed actuation as well as to evaluate other turbulence models that could capture the resonant effect. In concert with the development of more powerful 
actuators, the experimental testing of the concept in cascade should also be started.

In conclusion, this paper shows that plasma actuators are a promising technology in the development of more aggressive compressor blade design.

\section{Nomenclature}

Symbols

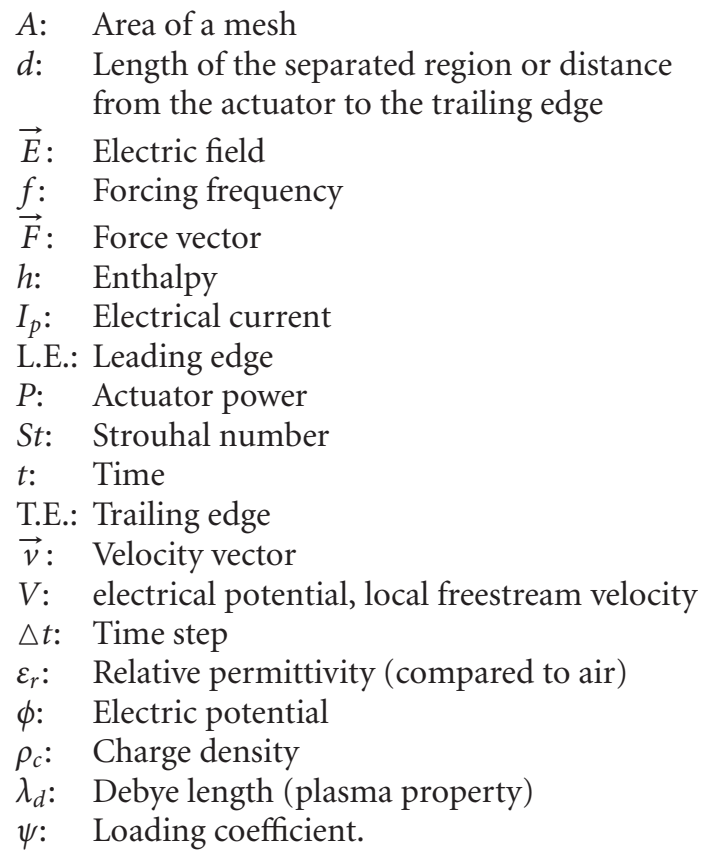

\section{Subscripts}

1: Inlet condition

2: Outlet condition

0 : Stagnation condition

$n$ : $n$th circuit in actuator model.

\section{Acknowledgments}

The authors would like to thank the National Research Council of Canada (NRC) and the Natural Sciences and Engineering Research Council of Canada (NSERC), whose funding made this research possible, Mr. O. Toukal for his assistance with the computational resources and $\mathrm{Mr}$. P. Versailles whose experimental work on plasma actuator allowed us to have confidence in our plasma actuator model.

\section{References}

[1] S. L. Dixon, Fluid Mechanics and Thermodynamics of Turbomachinery, Elsevier Butterworth-Heinemann, Amsterdam, The Netherlands, 5th edition, 1998.

[2] R. J. Loughery, R. A. Horn, and P. C. Tramm, "Single-stage experimental evaluation of boundary layer blowing and bleed techniques for high lift stator blades," Tech. Rep. NASA CR54573, Lewis Research Center, Cleveland, Ohio, USA, 1971.

[3] A. Merchant, J. L. Kerrebrock, J. J. Adamczyk, and E. Braunscheidel, "Experimental investigation of a high pressure ratio aspirated fan stage," ASME Journal of Turbomachinery, vol. 127, no. 1, pp. 43-51, 2005.

[4] B. J. Schuler, J. L. Kerrebrock, and A. Merchant, "Experimental investigation of a transonic aspirated compressor," ASME Journal of Turbomachinery, vol. 127, no. 2, pp. 340-348, 2005.

[5] T. Q. Dang, M. Van Rooij, and L. M. Larosiliere, "Design of aspirated compressor blades using three-dimensional inverse method," Tech. Rep. NASA TM-2003-212212, NASA Glenn Research Center, Cleveland, Ohio, USA, 2003.

[6] D. E. Culley, E. P. Braunscheidel, and M. M. Bright, "Impulsive injection for compressor stator separation control," Tech. Rep. NASA TM-2005-213859, NASA Glenn Research Center, Cleveland, Ohio, USA, 2003.

[7] J. Huang, T. C. Corke, and F. O. Thomas, "Unsteady plasma actuators for separation control of low-pressure turbine blades," AIAA Journal, vol. 44, no. 7, pp. 1477-1487, 2006.

[8] H. D. Vo, "Suppression of short length-scale rotating stall inception with glow discharge actuation," Proceedings of the ASME Turbo Expo, vol. 6, pp. 267-278, 2007.

[9] S. C. Morris, T. C. Corke, D. VanNess, J. Stephens, and T. Douvillet, "Tip clearance control using plasma actuators," in Proceedings of the 43rd AIAA Aerospace Sciences Meeting and Exhibit, pp. 14069-14076, Reno, Nev, USA, January 2005, AIAA Paper 2005-782.

[10] S. Lemire and H. D. Vo, "Reduction of fan and compressor wake defect using plasma actuation for tonal noise reduction," in Proceedings of the ASME Turbo Expo, vol. 6, pp. 837-848, Berlin, Germany, June 2008, GT2008-50821.

[11] C. L. Enloe, T. E. McLaughlin, R. D. VanDyken, K. D. Kachner, E. J. Jumper, and T. C. Corke, "Mechanisms and responses of a single dielectric barrier plasma," in Proceedings of the 41st Aerospace Sciences Meeting and Exhibit, Reno, Nev, USA, January 2003, AIAA Paper 2003-1021.

[12] T. C. Corke and M. L. Post, "Overview of plasma flow control: concepts, optimization, and applications," in Proceedings of the 43rd AIAA Aerospace Sciences Meeting and Exhibit, pp. 1320513219, Reno, Nev, USA, January 2005, AIAA Paper 2005-563.

[13] S. Roy and D. V. Gaitonde, "Modeling surface discharge effects of atmospheric RF on gas flow control," in Proceedings of the 43rd AIAA Aerospace Sciences Meeting and Exhibit, pp. 58155823, Reno, Nev, USA, 2005, AIAA Paper 2005-0160.

[14] B. Jayaraman, S. Thakur, and W. Shyy, "Modeling of dielectric barrier discharge and resulting fluid dynamics," in Proceedings of the 44th AIAA Aerospace Sciences Meeting, vol. 11, pp. 81738192, Reno, Nev, USA, January 2006, AIAA Paper 2006-686.

[15] G. I. Font, S. Jung, C. L. Enloe, T. E. McLaughlin, W. L. Morgan, and J. W. Baughn, "Simulation of the effects of force and heat produced by a plasma actuator on neutral flow evolution," in Proceedings of the 44th AIAA Aerospace Sciences Meeting, vol. 3, pp. 2018-2026, Reno, Nev, USA, January 2006, Paper 2006-167.

[16] W. Shyy, B. Jayaraman, and A. Andersson, "Modeling of glow discharge-induced fluid dynamics," Journal of Applied Physics, vol. 92, no. 11, pp. 6434-6443, 2002.

[17] Y. B. Suzen, P. G. Huang, J. D. Jacob, and D. E. Ashpis, "Numerical simulation of plasma based flow control applications," in Proceedings of the 35th AIAA Aerospace Science Meeting and Exhibit, Reno, Nev, USA, January 2006, AIAA Paper 20054633. 
[18] D. M. Orlov, T. Apker, C. He, H. Othman, and T. C. Corke, "Modeling and experiment of leading edge separation control using SDBD plasma actuators," in Proceedings of the 45th AIAA Aerospace Sciences Meeting, vol. 15, pp. 10651-10668, Reno, Nev, USA, January 2007.

[19] D. M. Orlov, Modeling and simulation of single dielectric barrier discharge plasma actuators, Ph.D. thesis, University of NotreDame, Notre-Dame, Ind, USA, 2006.

[20] S. Lemire, Amelioration de la performance des compresseurs et des soufflantes par actionnement plasma, M.S. thesis, Ecole Polytechnique de Montreal, Montreal, Canada, 2008.

[21] D. V. Gaitonde, M. R. Visbal, and S. Roy, "A coupled approach for plasma-based flow control simulations of wing sections," in Proceedings of the 44th AIAA Aerospace Sciences Meeting, vol. 19, pp. 14658-14677, Reno, Nev, USA, January 2006, AIAA Paper 2006-1205.

[22] S. Roy, K. P. Singh, H. Kumar, D. V. Gaitonde, and M. Visbal, "Effective discharge dynamics for plasma actuators," in Proceedings of the 44th AIAA Aerospace Sciences Meeting, vol. 6, pp. 4386-4397, Reno, Nev, USA, January 2006, AIAA Paper 2006-374.

[23] H. D. Vo, "Control of rotating stall in axial compressors using plasma actuators," in Proceedings of the 37th AIAA Fluid Dynamics Conference, vol. 1, pp. 1-15, Miami, Fla, USA, June 2007, AIAA Paper 2007-3845.

[24] J. D. Denton, "The use of a distributed body force to simulate viscous effects in 3D flow calculations," in Proceedings of the International Gas Turbine Conference and Exhibit, Duesseldorf, Germany, 1986, ASME Paper 86-GT-144.

[25] S. Lieblein, F. C. Schwenk, and R. L. Broderick, "Diffusion factor for estimating losses and limiting blade loadings in axial-flow-compressor blade elements," Tech. Rep. NASA RM E53D01, Lewis Flight Propulsion Laboratory, Cleveland, Ohio, USA, 1953.

[26] J. W. Baughn, C. O. Porter, B. L. Peterson, et al., "Momentum transfer for an aerodynamic plasma actuator with an imposed boundary layer," in Proceedings of the 44th AIAA Aerospace Sciences Meeting, vol. 3, pp. 2027-2041, Reno, Nev, USA, January 2006, AIAA Paper 2006-168.

[27] C. O. Porter, J. W. Baughn, T. E. McLaughlin, C. L. Enloe, and G. I. Font, "Temporal force measurements on an aerodynamic plasma actuator," in Proceedings of the 44th AIAA Aerospace Sciences Meeting, vol. 2, pp. 1310-1324, Reno, Nev, USA, January 2006, AIAA Paper 2006-104.

[28] D. F. Opaits, G. Neretti, A. V. Likhanskii, et al., "Experimental investigation of DBD plasma actuators driven by repetitive high voltage nanosecond pulses with DC or low-frequency sinusoidal bias," in Proceedings of the 38th AIAA Plasmadynamics and Lasers Conference, vol. 2, pp. 1039-1059, Miami, Fla, USA, June 2007, AIAA Paper 2007-4532.

[29] A. V. Likhanskii, M. N. Shneider, D. F. Opaits, R. B. Miles, and S. O. Macheret, "Numerical modeling of DBD plasma actuators and the induced air flow," in Proceedings of the 38th AIAA Plasmadynamics and Lasers Conference, vol. 2, pp. 1060 1072, Miami, Fla, USA, June 2007, AIAA Paper 2007-4533. 

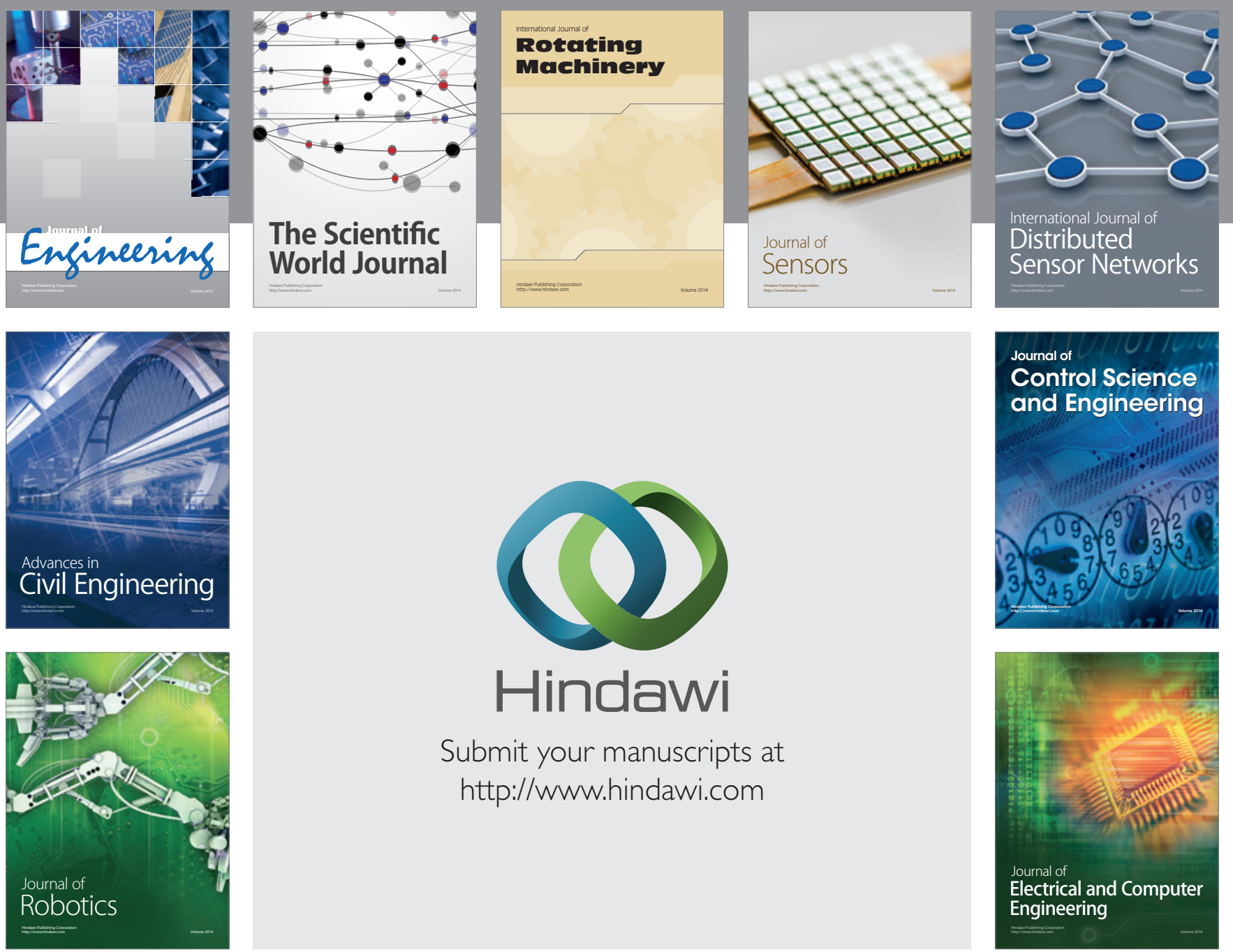

Submit your manuscripts at

http://www.hindawi.com
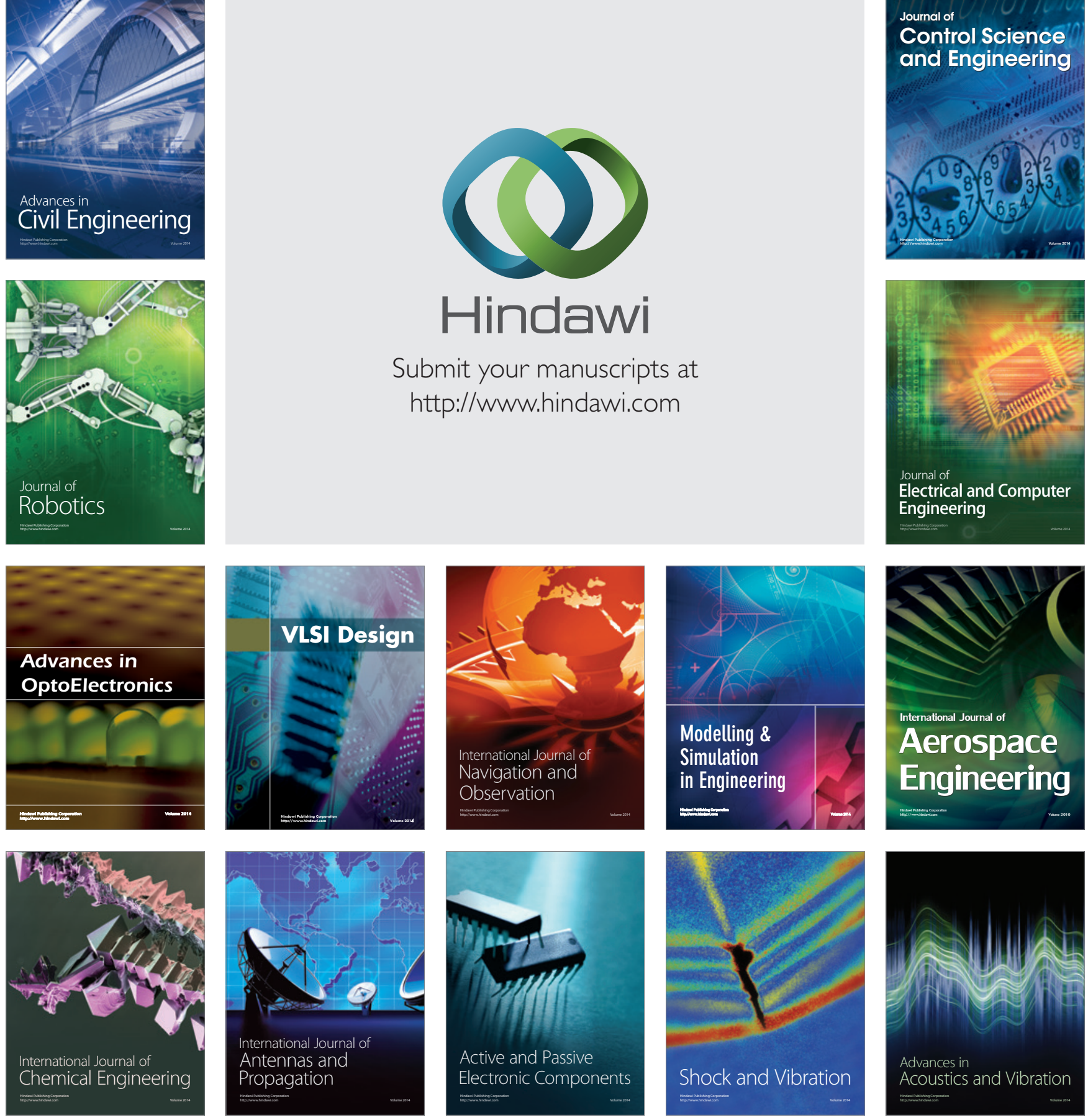